${ }^{1}$ Научно-исследовательский институт урологии и интервенционной радиологии

им. Н.А. Лопаткина, филиал Национального медицинского

исследовательского радиологического центра (Москва, Россия)

${ }^{2}$ Ростовский научноисследовательский онкологический институт (Ростов-на-Дону, Россия)
ВОЗМОЖНОСТИ ЗАМЕСТИТЕЛЬНОЙ ГОРМОНАЛЬНОЙ ТЕРАПИИ У ПАЦИЕНТОВ С АНАМНЕЗОМ ОНКОЛОГИЧЕСКИХ ЗАБОЛЕВАНИЙ

Н.Е. Левченко ${ }^{1}$, Е.А. Ефремов ${ }^{1}$, Е.В. Касатонова ${ }^{1}$, Ю.Р. Сидоренко ${ }^{2}$, Я.И. Мельник ${ }^{1}$, А.В. Корякин ${ }^{1}$

\section{HORMONE REPLACEMENT THERAPY IN PATIENTS WITH A HISTORY OF CANCER}

Н.Е. Левченко ${ }^{1}$ Доктор медицинских наук, профессор, руководитель группы репродуктивных технологий, отдел андрологии и репродукции человека, НИИ урологии и репродукции человека, НИИ урологии и интервенционной радиологии им. Н.А. Лопаткина, филиал НМИЦ радиологии Минздрава России, 105425, Москва, ул. Парковая 3-я, 51, стр. 1. SPIN-код: 9905-3077.

Е.A. Ефремов Доктор медицинских наук, заведуюший отделом андрологии и репродукции человека; профессор, кафедра урологии, андрологии и онкоурологии, РНИМУ им. Н.И. Пирогова Минздрава России.

Е.В. Касатонова ${ }^{1}$ Научный сотрудник, отдел андрологии и репродукции человека. E-mail:kasatonova@yandex.ru. SPIN-код: 3045-8375.

Ю.P. Сидоренко Академик РАН, главный научный сотрудник, Ростовский научно-исследовательский онкологический институт Минздрава России, 344037, Ростовская область, Ростов-на-Дону, 14-я линия, 63. SPIN-код: 0004-2485.

Я.И. Мельник ${ }^{1}$ Научный сотрудник, отдел андрологии и репродукиии человека. SPIN-код: 5662-2515.

A.В. Корякин ${ }^{1}$ Научный сотрудник, отдел онкоурологии. SPIN-код: 9627-0808.

N.E. Levchenko ${ }^{1}$ Doctor of Medicine, Professor, Head of Reproduction Research Group, Department of Andrology and Human Reproductive Health, Lopatkin Research Institute of Urology and Interventional Radiology, Branch of National Medical Research Radiology Center of the Ministry of Health of Russia, 105425, Moscow, 3-rd Parkovaya ul. 51. SPIN code: 9905-3077. 


$$
\begin{array}{r}
\text { E.A. Efremov } \\
\text { Doctor of Medicine, } \\
\text { Head of the Department of Andrology } \\
\text { and Human Reproductive Health; } \\
\text { Professor, } \\
\text { Department of Urology, Andrology and Oncourology, } \\
\text { Pirogov Russian National Research } \\
\text { Medical University. } \\
\text { E.V. Kasatonova }{ }^{1} \\
\text { Researcher, } \\
\text { Department of Andrology } \\
\text { and Human Reproductive Health, } \\
\text { E-mail: kasatonova@ya.ru. } \\
\text { SPIN code: 3045-8375. }
\end{array}
$$

Yu.S. Sidorenko ${ }^{2}$

Professor, Member of the Presidium of the Southern Scientific Centre of the Russian Academy of Sciences, Senior Researcher, Rostov Cancer Research Institute of Ministry of Health of Russia, 344037, Rostov-on-Don, 14-liniya 63. SPIN code: 0004-2485.

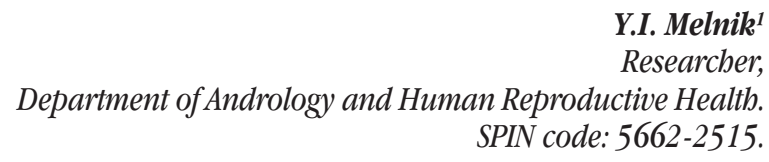

A.V. Koryakin ${ }^{1}$ Researcher, Department of Oncourology, SPIN code: 9627-0808.

Нарушение гормонального фона является признанным поздним осложнением у пациентов с онкологическим анамнезом. Дефицит гормонов влияет на качество жизни, нарушает кардиометаболическое и психологическое здоровье с дальнейшим увеличением заболеваемости и смертности, повышает риски сексуальной дисфункции и бесплодия. Расширение показаний к использованию заместительной гормональной терапии (ЗГТ) в этой когорте пациентов активно обсуждается. Большинство существующих клинических руководств содержат разделы по ЗГТ, однако насколько они применимы у мужчин и женщин, имеющих в анамнезе онкологическую патологию, часто неочевидно. В этой обзорной статье мы попытались систематизировать имеющиеся данные для наиболее часто встречающихся онкологических заболеваний в контексте возможностей применения ЗГТ для мужчин и женщин.

Ключевые слова: заместительная терапия, тестостерон, эстроген, гормональная терапия, онкология, ЗГТ.

Primary gonadal insufficiency is a recognized late effect in patients with an oncological history. Hormone deficiency affects the quality of life, cardiometabolic and psychological health with a further increase in morbidity and mortality, increases the risks of sexual dysfunction and infertility. The expansion of the indications for hormone replacement therapy (HRT) is a point to be discussed. Most of the existing clinical guidelines contain chapters on HRT, however, it is not clear in the context of young women with premature ovarian failure or men with testicular insufficiency due to cancer or its treatment. In this review we tried to systematize the available data for the most common oncological diseases, depending on the possibilities of using HRT for men and women.

Keywords: cancer survivor, estrogen replacement, testosterone replacement, HRT, bormone replacement therapy, MHT, menopausal bormone therapy, recurrence risk.

$\mathrm{H}$ а сегодняшний день доступно большое количество рандомизированных клинических исследований (РКИ) и сформированы рекомендации основных профессиональных сообществ по эффективности и безопасности заместительной гормональной терапии (ЗГТ) у мужчин и женщин, в том числе репродуктивного возраста [1-9].

Менопаузальная гормональная терапия (МГТ) у женщин одобрена в качестве первой линии для облегчения симптомов менопаузы, эффективна для предотвращения потери костной массы и снижения частоты переломов, снижения выраженности мочеполовых симптомов $[1,5,6]$. Североамериканское общество менопаузы (NAMS), при поддержке многих других профессиональных сообществ на нескольких континентах, утвердил применение ЗГТ без противопоказаний у женщин с гипогонадизмом, преждевременной недостаточностью яичников или хирургической менопаузой с доказанными преимуществами в улучшении качества жизни при симптомах менопаузы. В этой группе женщин МГТ применима для профилактики потери костной массы, сохранения когнитивной функции и настроения, а также для профилактики сердечной патологии, изучаемых в обсервационных исследованиях. По заключению NAMS, наибольшую выгоду с наименышими рисками извлекут из МГТ женщины младше 60 лет или находящиеся менее 10 лет в менопаузе. Потенциальные риски ГТ для этой группы женщин включают: низкий риск рака молочной железы при комбинированной МГТ, рак и гиперплазию эндометрия, венозную тромбоэмболию (ВТЭ) и патологию желчного пузыря. Дополнительные возрастные риски включают: инфаркт миокарда, инсульт и деменцию $[5,6]$.

Препараты тестостерона показаны для заместительной терапии у взрослых мужчин (ТЗТ) для состояний, связанных с дефицитом или отсутствием эндогенного тестостерона: первичного гипогонадизма - врожденного или приобретенного (тестикулярной недостаточности вследствие крипторхизма, орхиэктомии, синдрома Клайнфелтера, химиотерапии или другого токсического или лучевого повреждения) и гипогонадотропного гипогонадизма (центральные формы нарушения оси гипофиз-гипоталамус при 
травмах и опухолях, облучении). Лечение тестостероном может улучшить строение тела, минерализацию костей, гликемический контроль и липидный профиль, сексуальную функцию, память и депрессивные симптомы. Снижение ИМТ и размера талии наблюдаются у мужчин с гипогонадизмом, получающих лечение тестостероном [2]. Эндокринологическое общество (The Endocrine Society) не рекомендует назначать терапию тестостероном всем мужчинам старше 65 лет с низкими концентрациями тестостерона [3]. Другие руководства не так категоричны, но предлагают снижение веса, изменение образа жизни, контроль сопутствующих заболеваний и взвешенный подход к сердечно-сосудистым рискам в качестве первой линии терапии [2]. Риски для мужчин на ТЗТ включают рак предстательной железы, рак молочной железы, усиление симптомов доброкачественной гиперплазии предстательной железы (ДГПЖ), повышенный риск обструктивного апноэ сна. Мужчины, получающие Т3Т, должны мониторироваться на возможное наличие побочных эффектов таких, как полицитемия, периферические отеки, сердечная и печеночная дисфункция [2, 8].

Риски регистрируются не только при неадекватном и смелом назначении ЗГТ, но и при отсутствии терапии. Менопаузальный переход увеличивает подверженность метаболическим заболеваниям, таким, как ожирение, диабет, сердечно-сосудистая патология и рак. Ранняя менопауза снижает не только качество, но и продолжительность жизни [11]. Аналогично выявлена связь между более низкими концентрациями тестостерона с более высоким риском смертности от всех причин, особенно от сердечно-сосудистых заболеваний. Низкий уровень тестостерона у мужчин связан с увеличением артериального давления, дислипидемией, атеросклерозом, аритмией, тромбозом, дисфункцией эндотелия, а также с нарушением функции левого желудочка. Однако ТЗТ пока не доказала свою эффективность в отношении сердечно-сосудистых заболеваний, также, как и не было достоверно показано, что он имеет специфические неблагоприятные сердечнососудистые эффекты $[8,12]$. Несмотря на риски, которые несет в себе гонадодефицит и преимущества ЗГТ, терапия не должна быть расценена как мера профилактики сахарного диабета или сердечно-сосудистых заболеваний $[5,7,8]$.

За прошедшие десятилетия хорошо исследованы риски возникновения онкологической патологии, которую несет ЗГТ, хотя утверждать, что консенсус найден по всем вопросам, рано. Ситуация намного сложнее, когда речь идет о пациентах с онкологическим анамнезом. Эти пациенты гораздо чаще испытывают гонадодефицит как следствие лечения рака (хирургического лечения, химиотерапии или лучевой терапии), в результате самого заболевания, не связанного с онкологией, или просто достигают возрастного порога гормонодефицита. Считается, что механизм гипогонадизма у онкологических больных многофакторный. Пациенты с раком могут иметь компонент обоих типов гипогонадизма: первичный (гипергонадотропный или с повышенным лютеинизирующим гормоном - ЛГ - и фолликулярным стимулирующим гормоном - ФСГ) и вторичный (центральный, гипогонадотропный или с низким и ненадлежащим образом нормальным ФСГ и ЛГ). Факторы, связанные с первичным гипогонадизмом, включают воспалительные цитокины и химиотерапию. За вторичный/ центральный гипогонадизм ответственны опиоиды и глюкокортикостероиды $[13,14]$.

Существуют некоторые трудности при выявлении симптомов гормонального дефицита у онкологических пациентов, так как они субъективны и переплетаются с прочей симптоматикой. В одном исследовании существенно больше женщин (95,5\%), чем мужчин (40,6\%) после постановки диагноза получали ЗГТ, что может свидетельствовать о том, что женщины имеют более очевидный маркер первичной гонадной недостаточности - нарушение менструального цикла [13]. В онкологической литературе часто можно встретить утверждение, что клетки Лейдига, которые участвуют в секреции тестостерона в яичке, более устойчивы к химиолучевой терапии в отличии от герминогенного эпителия, производящего сперматозоиды. Упоминается, что, если мальчик достиг половой зрелости до лечения рака, то ТЗТ может не потребоваться [14]. Это не совсем справедливо: важно отметить, что многие дети после лечения рака обычно достигают половой зрелости, в том числе демонстрируют вторичные половые признаки развития. Однако это необязательно означает нормальное репродуктивное здоровье, поэтому гипогонадизм и нарушение фертильности должны оцениваться отдельно [13].

Решение о ЗГТ у пациента может базироваться на:

- известных рисках ЗГТ в патогенезе развития данного вида онкологической патологии;

- известных РКИ по применению ЗГТ при данном заболевании.

Обзор и формирование рекомендаций по ЗГТ было бы логично выстроить на основании присутствия или отсутствия в опухолях специфических гормональных рецепторов. На сегодняшний день эта задача невыполнима, главным образом, из-за отсутствия стандартизированных методов измерения эстрогеновых (ЭР) и андрогеновых (АР) рецепторов, малого количества пациентов и отсутствия продуманных РКИ. Наличие гормона и его рецептора недостаточно, чтобы предсказать эффект в клетках любого типа. Давно известно, что статус рецептора эстрогена, прогестерона и андрогена является важным прогностическим фактором, и используется для определения режима терапии при некоторых типах рака, например, молочной или предстательной желез. Тем не менее, сверхэкспрессия рецепторов была найдена не 
только в известных эстроген- или андрогензависимых типах опухолей. Измененная экспрессия рецептора эстрогена и/или прогестерона была зафиксирована при раке щитовидной железы, лимфоме Ходжкина, В-клеточных злокачественных новообразованиях, опухолях головного мозга, меланоме, раке легкого и опухолях желудочно-кишечного тракта $[15,16]$. Аналогичным образом регистрируется высокая частота обнаружения сверхэкспрессии андрогеновых рецепторов при раке молочной железы, яичников, щитовидной железы, меланоме, базальноклеточной карциноме, десмоидных опухолях и т. д. [15].

При опухолях, не связанных с репродуктивной системой, исследования рецепторов представлены отдельными клиническими случаями и очень небольшими выборками. Эти работы немногочисленны, поскольку, как показывают исследования, степень экспрессии рецепторов не всегда коррелирует с полом, размером и гистологическим типом опухоли, показателями выживаемости, что ставит под сомнение клиническую выгоду пациента [17]. Учитывая естественный гормональный фон, влияние ЗГТ на иммунный ответ и метастазирование практически непредсказуемо, поэтому клинические исследования и их правильная интерпретация должны быть учтены при принятии решения о ЗГТ, а не наличие сверхэкспресии рецептора как такового. Далее мы попытаемся систематизировать известные на сегодняшний день данные.

\section{Рак легких}

В настоящее время нет исследований по изучению ЗГТ у пациенток с наличием рака легких в анамнезе. В последние десятилетия он стал рассматриваться с позиции эстрогензависимого новообразования, и эстроген считается фактором развития и прогрессирования рака легких. Результаты эпидемиологических исследований позволяют предположить, что әстроген отрицательно влияет на прогноз пациентов с аденокарциномой легкого [18], а заместительная гормональная терапия эстрогенами была отмечена как фактор риска неблагоприятного исхода у женщин с данной патологией [19]. Тем не менее, существуют доказательства, связывающие комбинированную терапию эстрогенами и гестагенами до постановки диагноза с улучшением выживаемости [20]. Все же из-за недостаточности доказательной базы МГТ не должна использоваться у пациенток с раком легкого.

Результаты исследования 4165 мужчин в возрасте 70-88 лет показали, что повышение уровня тестостерона может быть связано с повышенным риском развития рака легких [21], а использование андрогендепривационной терапии (АДТ) у пациентов с раком простаты приводит к снижению риска возникновения метастатического и первичного рака легких [22]. Учитывая эти данные, стоит воздержаться от ТРТ у мужчин с данной патологией.

\section{Опухоли головного мозга}

По имеющимся на сегодняшний день данным, менингиома и глиома могут быть чувствительны к әстрогену и даже в большей степени к прогестерону, а гормоны могут стимулировать их рост и провоцировать рецидив. Использование МГТ может быть связано с повышенным риском их возникновения данных опухолей. Blitshteyn et al. обнаружили значительный 2-кратный повышенный риск менингиомы в группе более чем 355 тысяч женщин с текущим либо используемым в прошлом приемом МГТ, включая 1390 случаев менингиомы [23]. Менингиомы могут увеличиваться в размерах в результате назначения прогестеронов, эстрогенов и андрогенов. В большой британской базе данных женщин в возрасте 50-79 лет ЗГТ только эстрогенами, но не комбинированными эстроген-гестагенными препаратами, повышала риск развития опухолей головного мозга: глиомы и менингиомы [24]. Тем не менее, в некоторых других исследованиях сообщалось, что применение половых стероидных гормонов не было связано с риском развития глиомы [25]. В российских рекомендациях по МГТ наличие менингиомы является противопоказанием для данного вида терапии [4]. МГТ не должна назначаться пациенткам с опухолями головного мозга.

Выявленное присутствие рецепторов тестостерона в различных частях мозга указывает на то, что тестостерон может влиять на рост клеток головного мозга. Менингиома диагностируется реже у мужчин, чем у женщин. В исследовании Schildkraut et al. не было обнаружено, что большинство оцениваемых экзогенных гормональных воздействий, включая алопецию у мужчин, ЛГРГ, антиандрогены, тестостерон, орхиэктомию, индивидуально связаны с риском развития менингиомы у мужчин. Тем не менее, распространенность каждого из этих воздействий была низкой, и оценка связей недостаточно убедительна [26]. Другими авторами обнаружено, что тестостерон стимулирует пролиферацию, миграцию и инвазию клеток глиобластомы посредством активации рецептора андрогена [27]. ТЗТ не должна рассматриваться у пациентов с опухолями головного мозга.

\section{Злокачественные гематологические заболевания}

В настоящее время высокодозная химиотерапия и трансплантация костного мозга или стволовых клеток (миелоаблативное кондиционирование) является единственным вариантом терапии для большинства злокачественных гематологических заболеваний. Рутинные миелоабляционные схемы, содержащие высокие дозы комбинаций алкилирующих агентов (циклофосфамид и мелфалан) считаются причиной бесплодия большинства взрослых пациентов любого пола. В когорте онкогематологических пациенток высока частота преждевременной недостаточности 
яичников и наблюдается в 90\% случаев, при этом восстановление функции яичников маловероятно. Исследований по применению МГТ у женщин с наличием в анамнезе гематологического рака немного, но результаты согласованы и последовательны: терапия эффективно снимает симптомы менопаузы, безопасна и не повышает риск рецидива у пациенток с первичной недостаточностью яичников после миелоаблативной терапии [28, 29]. Некоторые исследователи отметили, что пациентки, использовавшие ЗГТ, имели даже несколько сниженный риск прогрессирования, который может быть связан с благотворным влиянием әстрогенов на гемопоэтические клетки [28]. МГТ может быть использована у пациенток с наличием злокачественных гематологических заболеваний в анамнезе.

Мужской гипогонадизм регистрируется у трети пациентов, перенесших аллогенную трансплантацию стволовых клеток. Существует только одно РКИ: было изучено влияние 12-месячной заместительной терапии тестостероном у 30 молодых мужчин с наличием гематологического рака в анамнезе и с повышенным уровнем ЛГ и низким/ нормальным уровнем тестостерона. Авторы не нашли никаких значительных преимуществ и не рекомендовали ТЗТ [30]. Таким образом, ТЗТ может быть предложена в исключительных случаях.

\section{Новообразования кожи. Меланома}

Злокачественная меланома является одной из самых агрессивных опухолей. Различия в динамике прогрессирования заболевания у женщин и мужчин хорошо известны: мужчины, несмотря на более низкую частоту заболеваемости, как правило, демонстрируют более быстрое прогрессирование и раннее метастазирование, приводящие к увеличению смертности и снижению выживаемости. Эти наблюдения могут частично объяснить потенциальную защитную роль эстрогенов в генезе меланомы и отсутствие выявленных рисков. По имеющимся данным, МГТ только эстрогенами, но не комбинированными эстроген-гестагенными препаратами, повышала риск развития меланомы кожи. Возможным объяснением противоречий может стать роль типа эстрогеновых рецепторов: ЭР типа $\alpha$ связаны с пролиферативным и стимулирующим опухоль эффектом, ЭР- $\beta$ обладают противоопухолевым эффектом [31]. Известно об одном исследовании, в котором наблюдали в течение 5 лет 206 пациенток, страдающих меланомой кожи I-II стадии. Однофакторный анализ показал значительную разницу в выживаемости в пользу группы,

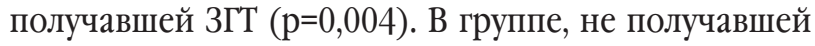
ЗГТ, отмечена более высокая доля язвенных первичных опухолей, признанных основным прогностическим фактором [32]. По всей видимости, у женщин с локализованными формами, МГТ может применяться с осторожностью, тогда как у пациенток с метастатическими формами, в связи с отсутствием данных, стоит воздержаться от лечения.

В исследованиях in vitro показано умеренное ингибирующее влияние тестостерона на рост клеток меланомы мыши [15]. Напротив, Morvillo et al. продемонстрировали рост опухоли в клеточных линиях меланомы человека после воздействия дигидротестостерона в сравнении со значительным ингибированием пролиферации после тамоксифена или флутамида [33]. В отсутствии данных следует воздерживаться от ТЗТ у мужчин с наличием меланомы в анамнезе.

\section{Новообразования кожи. Базальноклеточная карцинома (БКК)}

МГТ является фактором риска для немеланомного рака кожи. Повышенный риск БКК был связан с поздним возрастом при естественной менопаузе, а также любым использованием климактерической гормональной терапии. Риск был наиболее повышен среди женщин, сообщивших о естественной менопаузе и использующих МГТ в течение 10 или более лет, по сравнению с женщинами, которые никогда не использовали МГТ [34].

Сообщается о высокой экспрессии АР при базальноклеточной карциноме [15], Т3Т может иметь отрицательное влияние.

\section{Рак щитовидной железы}

Хотя злокачественные новообразования щитовидной железы чаще встречаются у женщин, чем у мужчин, убедительных доказательств связи МГТ с данным раком получено не было [35]. Deli et al. в своем обзоре считают возможным МГТ терапию, в том числе, отмечая необходимость профилактики остеопороза [16]. Несмотря на высокую экспрессию АР [15] и ЭР при раке щитовидной железы, данных для формирования рекомендаций недостаточно.

\section{Новообразования желудочно-кишечного тракта}

Большинство работ посвящено рискам развития онкологических заболеваний на фоне использования МГТ, а не исследованию риска возникновения рецидива. Однако факт отсутствия достоверных статистических подтверждений канцеростимулирующего влияния эстрогенов на органы желудочно-кишечного тракта позволяет использовать гормональную терапию у онкологических пациентов данной группы [36].

\section{Рак поджелудочной железы (ПЖ)}

При раке поджелудочной железы обнаруживается сверхэкспрессия как ЭР, так и АР [37]. Пациентам с раком ПЖ стоит воздержаться от ЗГТ, поскольку недостаточно информации о безопасности данной терапии. 


\section{Рак пищевода (РП)}

Немногочисленные данные демонстрируют менопаузальный статус как фактор риска развития рака пищевода [38]. Недавнее исследование успешно продемонстрировало, что менопаузальная гормональная терапия снижает риск РП [39]. Опасения клиницистов в отношении риска развития РП на фоне приема МГТ не нашли своего подтверждения. Немногочисленная достоверная информация свидетельствует о протективном влиянии эстрогенов [36].

Рак пищевода чаще встречается у мужчин, чем у женщин. Представляет интерес тот факт, что база данных регистров Survival Epidemiology and End Results (SEER) показала, что у пациентов с раком простаты реже развивается аденокарцинома пищевода [40]. Данные, полученные в результате работы с клеточными культурами и последующим тестированием на мышиных моделях, свидетельствуют о значительном влиянии половых гормонов на прогрессию рака, и этот эффект согласуется с паттернами экспрессии рецепторов [41]. ТЗТ не должна применяться у мужчин с раком пищевода.

\section{Рак желудка}

Известно, что ЭР+ опухоли желудка связаны с худшими результатами терапии и связаны с более распространенными и менее дифференцированными типами опухолей [42]. Brusselaers et al., тем не менеe, не обнаружили снижение частоты аденокарциномы пищевода и желудка среди пациенток на моно- и комбинированной 3ГТ [39].

Экспрессия АР также связана с плохим прогнозом и снижением выживаемости [43]. Принимая во внимание все эти данные, следует избегать ЗГТ у пациентов с наличием рака желудка в анамнезе.

\section{Рак печени}

Первичный рак печени встречается реже среди женщин, чем среди мужчин. Это несоответствие предполагает, что уровни гормонов и/или использование экзогенных гормонов могут влиять на риск его возникновения. Использование МГТ было связано со значительно более низким риском рака печени [44]. Предыдущие результаты показали, что использование МГТ может снизить риск рака печени, поскольку МГТ обратно пропорционально связана с жировой болезнью печени, а также с уровнем ферментов печени у женщин в постменопаузе [45]. МГТ может быть использована у пациенток с наличием рака печени в анамнезе.

Преобладание мужчин с раком печени свидетельствует о том, что андрогены могут способствовать его развитию, тем не менее, на сегодняшний день известно только то, что АР, а не гормон, играет доминирующую роль в возникновении рака [46]. Т3Т не должна использоваться у мужчин с наличием рака печени в анамнезе.

\section{Колоректальный рак}

Несколько рецепторов половых гормонов, включая рецепторы андрогенов, прогестерона и эстрогена, экспрессируются в клетках пищеварительного тракта. В связи с этим, хотя колоректальный рак, как правило, не считается гормональным злокачественным новообразованием, накапливаются свидетельства того, что половые гормоны имеют отношение к его развитию. Эстроген оказывает защитное действие в патогенезе колоректального рака. Наблюдательные исследования предполагают снижение частоты возникновения колоректального рака у пациенток, принимающих МГТ, особенно если оно начато в начале менопаузы. Эти данные подтверждены в нескольких исследовательских работах $[47,48]$. Также регистрируется улучшение 5-летней выживаемости рака толстой кишки уженщин, которые использовали МГТ [48]. МГТ может использоваться у женщин с раком ободочной и прямой кишки.

Несмотря на попытки прояснить влияние тестостерона на развитие рака, отношения между эндогенным тестостероном и развитием рака до сих пор остается весьма спорным. Результаты недавнего исследования показывают, что различные дозы тестостерона могут оказывать усиление или подавление пролиферации клеток аденокарциномы толстой кишки [49]. Результаты исследования 4165 мужчин в возрасте 70-88 лет показали, что повышение уровня тестостерона может быть связано с повышенным риском развития рака легких, но не с риском развития рака толстой кишки [21]. Стоит воздержаться от ТЗТ у мужчин с анамнезом КРК.

\section{Новообразования мочевыделительной системы}

Роль сигнальной оси андрогена и АР долгое время ассоциировалась с развитием и прогрессированием рака предстательной железы, роль АР в почечно-клеточном раке и раке мочевого пузыря (РМП) на сегодняшний день также становится одной из актуальных тем исследований [50].

\section{Рак почек}

Абсолютное большинство случаев рака почки представлены почечно-клеточным раком (ПКР) с четкими гендерными различиями: у мужчин ПКР встречается почти в два раза чаще, чем у женщин, что также указывает на роль половых гормонов или их рецепторов в развитии и прогрессировании рака. Несколько исследований пришли к выводу, что нет никакой связи между МГТ и раком почки $[51,52]$. Женщинам, имеющим в анамнезе рак почки, может быть предложена МГТ.

Не обнаружено существенных различий в экспрессии АР в образцах нормальной ткани по сравнению с опухолевой. В среднем, пациенты с более высокими 
уровнями экспрессии АР имели более короткую выживаемость без прогрессирования и более низкие общие показатели выживаемости, что связывает экспрессию АР с плохим прогнозом [53]. В противоположность, другие данные свидетельствовали о том, что экспрессия АР коррелировала с благоприятной патологической стадией и общим благоприятным прогнозом [54]. В отсутствие данных, не стоит предлагать ТЗТ пациентам с раком почки.

\section{Рак мочевого пузыря}

Эпидемиологические данные убедительно подтверждают идею о том, что мужчины подвержены повышенному риску развития рака мочевого пузыря по сравнению с женщинами вне зависимости от статуса курения, хотя было показано, что женщины имеют более продвинутые стадии заболевания [55]. РмП следует рассматривать как чувствительную к эстрогену опухоль. Имеются данные о том, что использование МГТ в анамнезе удваивало риск развития рака мочевого пузыря [45]. МГТ не должна назначаться женщинам с историей РМП.

Последние публикации свидетельствуют о том, что сигнальный путь АР играет роль в развитии и прогрессировании рака мочевого пузыря, что побуждает некоторых ученых исследовать его потенциал в качестве терапевтической мишени [50]. Во время динамического наблюдения пациенты, получавшие АДТ, имели достоверно более низкую частоту рецидивов РМП [56]. ТЗТ не должна назначаться мужчинам с РМП.

\section{Рак молочной железы}

Пожалуй, МГТ после перенесенного рака молочной железы является наиболее исследуемой и обсуждаемой темой, несмотря на категоричное положение всех существующих руководств: ЗГТ при раке молочной железы противопоказана как у мужчин, так и у женщин [1-9]. Использование гормонов для лечения симптомов менопаузы у пациенток с наличием рака молочной железы (РМЖ) в анамнезе очень спорно, так как стандартная адъювантная терапия включает депривацию эстрогена с тамоксифеноми/ или ингибиторами ароматазы для предотвращения рецидива заболевания [57]. В целом, влияние МГТ на риск рака молочной железы может зависеть от типа ГТ, дозы, длительности применения, режима, типа введения, предварительного воздействия, и именно такая гетерогенность имеющихся данных мешает прийти к консенсусу. Систематический обзор [58] предполагает, что МГТ после рака молочной железы не увеличивает риск рецидива. В противовес вышеперечисленным исследованиям, широко цитируемое РКИ HABITS [59] было досрочно прекращено из-за высокой частоты рецидивов в группе МГТ $(17,5 \%)$, и вынудило другое стокгольмское исследование также досрочно завершить проект [60], хотя исследование не показало повышенный риск рецидива или смерт- ности при МГТ (ОШ 0,82).В последующем расширенный анализ HABITS и Стокгольмского исследования указывали на повышенный риск контрлатерального рака или рецидива рака молочной железы после различных схем 3ГТ с относительным риском рецидива от 2,0 до 3,6 [59, 60]. NAMS допускает отдельные случаи применения МГТ (системную низкодозированную) с вескими причинами после обсуждения с онкологом [5]. Текущие российские клинические рекомендации рассматривают РМЖ как строгое противопоказание [4].

Не существует известной патогенетической связи тестостерона непосредственно с развитием рака молочной железы. Однако он может быть ароматизирован до эстрадиола, который усиливает пролиферацию и, в итоге, может стимулировать рецепторы ткани молочной железы и увеличить риск рака молочной железы у мужчин. В одном ретроспективном обзоре отмечается $11 \%$ случаев у 45 мужчин при длительной ТРТ в течение 10 лет [61]. ТЗТ противопоказана мужчинам, перенесшим РМЖ.

\section{Новообразования в гинекологии Рак эндометрия}

Ретроспективный анализ, а также РКИ не выявили повышенный риск рецидива или смертности, связанных с различными комбинациями МГТ для пациенток с наличием в анамнезе рака эндометрия I-II стадии $[29,62]$. При метаанализе было отмечено, что комбинация эстрогенов и прогестинов имела защитный противорецидивный эффект, который не обеспечивала монотерапия только эстрогенами [63]. Текущие российские клинические рекомендации отмечают РЭ как противопоказание к моно-МГТ эстрогенами. Сопутствующий гестаген рекомендуется для женщин с интактной маткой при использовании системной ЭТ $[4,5]$. Ограниченные данные свидетельствуют о том, что женщины с РЭ на ранней стадии могут получать МГТ.

\section{Рак яичников}

Злокачественные новообразования яичников гистологически очень различны, но примерно 90\% являются эпителиальными. Несколько исследований с наблюдением от 3,5 до 12 лет и их метаанализ показал, что МГТ не увеличивает рецидив злокачественного заболевания [64, 65], а в одной работе терапия даже значительно увеличивала выживаемость у пациенток [66]. Пациентки с гранулезоклеточной или эндометриоидными опухолями не рассматриваются как кандидатки на МГТ [57]. В случае лечения герминогенных опухолей считается, что ЗГТ не несут дополнительного риска рецидива [67]. У носителей мутации BRCA после двусторонней профилактической сальпингоофорэктомии с отсутствием в анамнезе рака молочной железы МГТ может быть предложена до возраста естественной менопаузы - 50 лет [68]. МГТ 
может быть рассмотрена у женщин с РЭ на ранней стадии (низкий риск).

\section{Рак шейки матки}

Преимущественное количество случаев рака шейки матки - плоскоклеточный рак, который как известно, не является эстрогензависимым. Нет данных, свидетельствующих о худшем прогнозе с МГТ после лечения плоскоклеточного рака или аденокарциномы шейки матки [69]. У женщин с сохраненной маткой целесообразно выбрать комбинированный режим әстроген-гестагенных препаратов [16]. По имеющимся данным, лечение рака шейки матки не является противопоказанием для МГТ.

\section{Рак вульвы и влагалища}

Плоскоклеточный рак вульвы и влагалища в значительной степени связан с ВПЧ и не является гормонозависимым; нет данных, свидетельствующих о вреде МГТ [67].

\section{Новообразования в андрологии Рак простаты}

Как и в случае с раком молочной железы, рак простаты (РПЖ) считается абсолютным противопоказанием к ТЗТ, однако гетерогенность исследований и несогласованность выводов заставляет обсуждать возможности гормональной терапии. В настоящее время андрогенная депривационная терапия остается краеугольным камнем лечения мужчин с распространенной формой РПЖ, поэтому неудивительно, что T3Т противопоказана мужчинам с диагностированным раком предстательной железы, а также пациентам высокого риска. Ранее считалось, что высокий уровень тестостерона приводит к потенциальному развитию РПЖ и более быстрому росту опухоли. Тем не менее, исследования связи между тестостероном и риском РПЖ дали противоречивые результаты [70]. В большом метаанализе 18 проспективных исследований, включавших более 3500 мужчин, не было никакой связи между сывороточным тестостероном и риском развития РПж [71]. В недавнем РКИ терапия тестостероном не приводила к значительному увеличению частоты рака простаты у пожилых мужчин с дефицитом тестостерона, по сравнению с теми, кто получал плацебо [72]. Многое объясняет теория насыщения Morgentaler et al.: рост опухоли простаты становится нечувствительным к изменениям на нормальных уровнях андрогенов из-за насыщения андроген-рецептора; тем не менее, на уровне кастрации наблюдается экспоненциальный рост [73]. Эта теория может объяснить, почему тестостерон не вызывает рак предстательной железы напрямую, но ускоряет развитие рака предстательной железы.

Для мужчин, которые ранее подвергались радикальному лечению рака простаты, использование ТЗТ становится все более приемлемым и не увеличивает риск рецидива несмотря на рост ПСА [74]. Для мужчин, находящихся под динамическим наблюдением, применение ТЗТ спорно. Европейская ассоциация урологов допускает назначение ТЗТ с осторожностью при наличии симптомов андрогенной недостаточности у мужчин после хирургического лечения рака простаты, брахитерапии и наружной лучевой терапии у пациентов с отсутствием признаков активного процесса и пациентам с низким риском рецидива рака простаты (индекс Глисона до операции <8 нг/мл, стадия Т1-2, уровень ПСА $<10$ нг/ мл) не ранее чем через 1 год после лечения при отсутствии биохимического рецидива [2]. Клинические рекомендации Российского общества урологов [9] и Российского общества эндокринологов [10] не поддерживают ЕАУ, поскольку качественные РКИ отсутствуют. ТЗТ при метастатическом раке не рассматривается и ее не следует назначать мужчинам с этими видами рака [3].

\section{Рак яичка}

Большинство пациентов после односторонней орхиэктомии скомпенсированы или демонстрируют пограничное значение уровней тестостерона с прогрессирующим ухудшением функции клеток Лейдига. Риск гипогонадизма значительно выше у пациентов, получавших химиотерапию, чем у пациентов, получавших лучевую терапию или только хирургическое вмешательство [75]. В недавнем мультицентровом исследовании в Северной Америке был оценен 491 мужчина с раком яичка в анамнезе: в относительно молодом медианном возрасте (38,2 года) более трети имели гипогонадизм, который в значительной степени был связан с повышенными факторами риска сердечно-сосудистых заболеваний и эректильной дисфункцией [76]. ТЗТ не противопоказана пациентам с признаками гипогонадизма с наличием рака яичка в анамнезе.

Таким образом, принятие решения относительно использования заместительной гормональной терапии (ЗГТ) для преодоления симптомов дефицита половых гормонов - клинически непростая задача, зачастую требующая персонифицированного подхода. Еще больше она усложняет у пациентов с наличием злокачественных заболеваний в анамнезе оценку риска рецидива и смертности. Рецепторы эстрогенов и андрогенов присутствуют в нескольких типах рака, но это не всегда приводит к гормон-опосредованной пролиферации опухоли и неблагоприятным последствиям, связанных с раком. Гормоны могут иметь и протекционный эффект. Если взглянуть на сводную таблицу, очевидно, что, в то время как МГТ может использоваться при достаточно обширном списке перенесенных онкологических заболеваний, ТЗТ по факту рассматривается только у мужчин с раком яичка в анамнезе - и это проблема отсутствия РКИ, а не опасности тестостерон-заместительной терапии как таковой. В то же время альтернативных вариантов 
Заключительные данные о возможсности использования ЗГТ у пациентов с историей злокачественных новообразований

\begin{tabular}{|l|l|l|}
\hline & \multicolumn{1}{|c|}{ женщины } & мужчины \\
\hline Рак легких & & \\
\hline Опухоли головного мозга & & \\
\hline $\begin{array}{l}\text { Злокачественные } \\
\text { гематологические заболевания }\end{array}$ & Локализованные формы & \\
\hline Меланома & & \\
\hline Базальноклеточная карцинома & & \\
\hline Рак щитовидной железы & & \\
\hline Рак поджелудочной железы & & \\
\hline Рак пищевода & & \\
\hline Рак желудка & & \\
\hline Рак печени & & \\
\hline Колоректальный рак & & \\
\hline Рак почек & & \\
\hline Рак мочевого пузыря & Низкого риска, 1-2 стадия, Э+П & \\
\hline Рак молочной железы & Низкого риска, 1-2 стадия, Э+П & \\
\hline Рак эндометрия & Э+П при интактной матке & \\
\hline Рак яичников & & \\
\hline Шейка матки & & \\
\hline Рак предстательной железы & & \\
\hline Рак яичника & & \\
\hline
\end{tabular}

Противопоказание или нет данных о безопасности

Ограниченные свидетельства

Возможно использовать с низкими рисками рецидива

терапии для мужчин и женщин не так много. В основном это изменение факторов образа жизни: здоровая диета, отказ от вредных привычек, нормализация веса, нормализация сна. Были также представлены: когнитивно-поведенческая терапия, йога, иглореф- лексотерапия и акупунктура. У женщин могут быть использованы фитоэстрогены, антидепрессанты, витаминные комплексы [1-10]. Необходимы дальнейшие исследования для расширения возможности применения ЗГТ.

\section{Список литературы}

1.Baber R.J., Panay N., FentonA. 2016 IMS Recommendations on women's midlife health and menopause hormone therapy // Climacteric. - 2016. - Vol. 19. - № 2. - P. 109-150.

2.Doble G., Colpi G., Hargreave T., Papp G., Jungwirth A,. Weidner W. European Association of Urology, Arnhem, The Netherlands, accessed Mar. - 2016. - Vol. 21. - P. 2018.

3. Bhasin S., Brito J.P., Cunningham G.R., Hayes F.J., Hodis H.N., Matsumoto A.M., Snyder P.J., Swerdloff R.S., Wu F.C., Yialamas M.A. Testosterone therapy in men with hypogonadism: an Endocrine Society clinical practice guideline // The Journal of Clinical Endocrinology \& Metabolism. - 2018. - Vol. 103. - № 5. - P. 1715-1744.

4. Сухих Г.Т., Сметник В.П., Андреева Е.Н., Балан В.Е., Гависова А.А., Григорян О.Р., Ермакова Е.И., Ильина Л.М., Марченко Л.А., Роговская Р.И., СметникА.А., Юренева Р.В. Менопаузальная гормонотерапия и сохранение здоровья женщин зрелого возраста. Клинические рекомендации: протоколы // Клинические рекомендации (протокол лечения). - М. - 2017. - Р. 30. 
5. Pinkerton J.V., Sánchez Aguirre F., Blake J., Cosman F., Hodis H.N., Hoffstetter S., Kaunitz A.M., Kingsberg S.A., Maki P.M., Manson J.E., Marchbanks P., McClung M.R., Nachtigall L.E., Nelson L.M., Pace D.T., Reid R.L., Sarrel P.M., Shifren J.L., Stuenkel C.A., Utian W.H. The 2017 hormone therapy position statement of the North American Menopause Society // Menopause. - 2017. - Vol. 24. - № 7. - P. 728-753.

6. Webber L., Davies M., Anderso P. ESHRE guideline: management of women with premature ovarian insufficiency // Reproductive Endocrinology. - 2017. - № 37. - P. 41-48.

7. Cobin R.H., Goodman N.F. Reproductive Endocrinology Scientific Committee (ARES) // American Association of Clinical Endocrinologists and American College of Endocrinology position statement on menopause - 2017 update. Endocr Pract. - 2017. - Vol. 23. - P. 869-880.

8. Dimopoulou C., Ceausu I., Depypere H., Lambrinoudaki I., Mueck A., Pérez-López F.R., Rees M., van der Schouw Y.T., Senturk L.M., Simonsini T., Stevenson J.C., Stute P., Goulis D.G. EMAS position statement: Testosterone replacement therapy in the aging male // Maturitas. - 2016. - Vol. 84. - P. 94-99.

9. Урология. Российские клинические рекомендации / под ред. Ю.Г. Аляева, П.В. Глыбочко, Д.Ю. Пушкаря. 2017. - 544 c.

10. Дедов И.И., Мельниченко Г.А., Роживанов Р.В., Курбатов Д.Г. Рекомендации по диагностике и лечению гипогонадизма (дефицита тестостерона) у мужчин. Проект // Проблемы эндокринологии. - 2015. - Т. 61. - № 5.

11. Roman L.A., Nascimento C., Oliveira D.Y., Porto C.F.A. Age at natural menopause and mortality: A survival analysis of elderly residents of São Paulo, Brazil // Maturitas. - 2018. - Vol. 117. - P. 29-33.

12. Ruige J.B., Ouwens D.M., Kaufman J.M. Beneficial and adverse effects of testosterone on the cardiovascular system in men // The Journal of Clinical Endocrinology \& Metabolism. - 2013. - Vol. 98. - № 11. - P. 4300-4310.

13. Gunn H.M., Rinne I., Emilsson H., Gabriel M., Maguire A.M., Steinbeck K.S. Primary gonadal insufficiency in male and female childhood cancer survivors in a long-term follow-up clinic // Journal of adolescent and young adult oncology. - 2016. - Vol. 5. - № 4. - P. 344-350.

14. Chisholm J., Hough R., Soanes L. (ed.). A Practical Approach to the Care of Adolescents and Young Adults with Cancer. - Springer International Publishing, 2018.

15. Munoz J., Wheler J.J., Kurzrock R. Androgen receptors beyond prostate cancer: an old marker as a new target // Oncotarget. - 2015. - Vol. 6. - № 2. - P. 592.

16. Deli T., Orosz M., Jakab A. Hormone Replacement Therapy in Cancer Survivors - Review of the Literature // Pathology \& Oncology Research. - 2019. - P. 1-16.

17. Богуш Т.А., Дудко Е.А., Бёме А.А., Богуш Е.А., Полоцкий Б.Е., Тюляндин Р.А., Давыдов М.И. Экспрессия эстрогеновых рецепторов в опухолях, отличных от рака молочной железы // Антибиотики и химиотерапия. 2009. - T. 54. - № 7-8.

18. Hsu L.H., Chu N.M., Kao S.H. Estrogen, estrogen receptor and lung cancer //International journal of molecular sciences. - 2017. - Vol. 18. - № 8. - P. 1713.

19. Ganti A.K., Sabmoun A.E., Panwalkar A.W., Tendulkar K.K., Potti A. Hormone replacement therapy is associated with decreased survival in women with lung cancer // Journal of clinical oncology. - 2006. - Vol. 24 . - № 1. - P. $59-63$.

20. Clague J., Reynolds P., Henderson K.D., Sullivan-Halley J., Ma H., Lacey J., Chang S., Delclos G.L., Du X., Forman M.R., Bernstein L. Menopausal hormone therapy and lung cancer-specific mortality following diagnosis: the California Teachers Study // PloS one. - 2014. - Vol. 9. - № 7. - P. e103735.

21. Hyde Z., Flicker L., McCaul K.A., Almeida O.P., Hankey G.J., Chubb S.A.P., Yeap B.B. Associations between testosterone levels and incident prostate, lung, and colorectal cancer. A population-based study // Cancer Epidemiology and Prevention Biomarkers. - 2012. - Vol. 21. - № 8. - P. 1319-1329.

22. Jung K., Park J.C., Kang H., Brandes J.C. Androgen deprivation therapy is associated with decreased second primary lung cancer risk in the United States veterans with prostate cancer // Epidemiology and health. - 2018. Vol. 40 .

23. Blitshteyn S., Crook J.E., Jaeckle K.A. Is there an association between meningioma and hormone replacement therapy? // Journal of Clinical Oncology. - 2008. - Vol. 26. - № 2. - P. 279-282.

24. Benson V.S., Kirichek O., Beral V., Green J. Menopausal hormone therapy and central nervous system tumor risk: Large UK prospective study and meta-analysis // International journal of cancer. - 2015. - Vol. 136. - № 10. P. 2369-2377.

25. Wigertz A., Lönn S., Matbiesen T., Ablbom A., Hall P., Feychting M. Risk of brain tumors associated with exposure to exogenous female sex hormones // American journal of epidemiology. - 2006. - Vol. 164. - № 7. - P. 629-636.

26. Schildkraut J.M., Calvocoressi L., Wang F., Wrensch M., Bondy M.L., Wiemels J.L., Claus E.B. Endogenous and exogenous hormone exposure and the risk of meningioma in men // Journal of neurosurgery. - 2014. - Vol. 120. № 4. - P. 820-826.

27. Rodríguez-Lozano D.C., Piña-Medina A.G., Hansberg-Pastor V., Bello-Alvarez C., Camacho-Arroyo I. Testosterone promotes glioblastoma cell proliferation, migration and invasion through androgen receptor activation // Frontiers in endocrinology. - 2019. - Vol. 10. - P. 16.

28. Ross J.A., Sinner P.J., Blair C.K., Cerban J.R., Folsom A.R. Hormone replacement therapy is not associated with an increased risk of leukemia (United States) // Cancer Causes \& Control. - 2005. - Vol. 16. - № 5. - P. 483-488.

29. Hinds L., Price J. Menopause, hormone replacement and gynaecological cancers // Menopause international. 2010. - Vol. 16. - № 2. - P. 89-93. 
30. Howell S.J., Radford J.A., AdamsJ.E., Smets E.M.A., Warburton R., Shalet S.M. Randomized placebo-controlled trial of testosterone replacement in men with mild Leydig cell insufficiency following cytotoxic chemotherapy // Clinical endocrinology. - 2001. - Vol. 55. - № 3. - P. 315-324.

31. Botteri E., Støer N.C., Weiderpass E., Pukkala E., Ylikorkala O., Lyytinen H. Menopausal hormone therapy and risk of melanoma: a nationwide register-based study in Finland // Cancer Epidemiology and Prevention Biomarkers. 2019. - P. cebp. 0554.2019.

32. MacKie R.M., Bray C.A. Hormone replacement therapy after surgery for stage 1 or 2 cutaneous melanoma // British journal of cancer. - 2004. - Vol. 90. - № 4. - P. 770.

33. Morvillo V., Lüthy I.A., Bravo A.I., Capurro M.I., Portela .P, Calandra R., Mordob J. Androgen receptors in human melanoma cell lines IIB-MEL-LES and IIB-MEL-IAN and in human melanoma metastases // Melanoma research. 2002. - Vol. 12. - № 6. - P. 529-538.

34. Caboon E.K., Kitahara C.M., Ntowe E., Bowen E.M., Doody M.M., Alexander B.H., Lee T., Little M.P., Linet M.S., Freedman D.M. Female estrogen-related factors and incidence of basal cell carcinoma in a nationwide US cohort // Journal of Clinical Oncology. - 2015. - Vol. 33. - № 34. - P. 4058.

35. Moleti M., Sturniolo G., Di Mauro M., Russo M., Vermiglio F. Female reproductive factors and differentiated thyroid cancer // Frontiers in endocrinology. - 2017. - Vol. 8. - P. 111.

36. Якушевская О.В., Юренева Р.В., Протасова А.Э., Хабас Г.Н., Ашрабян Л.А. Менопаузальная гормональная терапия и негинекологический рак (новообразования органов пищеварения) // Акушерство и гинекология: Новости. Мнения. Обучения. - 2019. - № 1(23).

37. Wibowo E., Schellhammer P., Wassersug R.J. Role of estrogen in normal male function: clinical implications for patients with prostate cancer on androgen deprivation therapy // The Journal of urology. - 2011. - Vol. 185. № 1. - P. 17-23.

38.Zbu Y., Yue D., Yuan B., Zbu L., LuM. Reproductive factors are associated with oesophageal cancer risk: results from a meta-analysis of observational studies // European Journal of Cancer Prevention. - 2017. - Vol. 26. - № 1. - P. 1-9.

39. Brusselaers N., Maret-Ouda J., Konings P., El-Serag H.B., Lagergren J. Menopausal hormone therapy and the risk of esophageal and gastric cancer // International journal of cancer. - 2017. - Vol. 140. № 7. - P. 1693-1699.

40. Cooper S.C., Trudgill N.J. Subjects with prostate cancer are less likely to develop esophageal cancer: analysis of SEER 9 registries database // Cancer Causes \& Control. - 2012. - Vol. 23. - № 6. - P. 819-825.

41. Sukocheva O.A. Androgens and esophageal cancer: What do we know? // World Journal of Gastroenterology: WJG. - 2015. - Vol. 21. - № 20. - P. 6146.

42. Kim H.W., Kim J., Lim B.J., Kim H., Kim H., Park J.J., Youn Y.H., Park H., Noh S.H., Kim J.W., Choi S.H. Sex disparity in gastric cancer: female sex is a poor prognostic factor for advanced gastric cancer // Annals of surgical oncology. 2016. - Vol. 23. - № 13. - P. 4344-4351.

43. Kominea A., Konstantinopoulos P.A., Kapranos N., Vandoros G., Gkermpesi M., Andricopoulos P., Artelaris S., Savva S., Varakis I., Sotiropoulou-Bonikou G., Papavassiliou A.G. Androgen receptor (AR) expression is an independent unfavorable prognostic factor in gastric cancer // Journal of cancer research and clinical oncology. - 2004. Vol. 130. - № 5. - P. 253-258.

44. Shi L., Feng Y., Lin H., Ma R., Cai X. Role of estrogen in hepatocellular carcinoma: is inflammation the key? // Journal of translational medicine. - 2014. - Vol. 12. - № 1. - P. 93.

45. Fernandez E., Gallus S., Bosetti C., Franceschi S., Negri E., La Vecchia C. Hormone replacement therapy and cancer risk: a systematic analysis from a network of case-control studies // International journal of cancer. - 2003. Vol. 105. - № 3. - P. 408-412.

46. Ma W., Lai H., Yeb S., Cai X., Chang C. Androgen receptor roles in hepatocellular carcinoma, cirrhosis, and hepatitis // Endocrine-related cancer. - 2014. - Vol. 21. - № 3. - P. R165.

47. Prentice R.L., Pettinger M., Beresford S.A., Wactawski-Wende J., Hubbell F.A., Stefanick M.L., Cblebowski R.T. Colorectal cancer in relation to postmenopausal estrogen and estrogen plus progestin in the Women's Health Initiative clinical trial and observational study // Cancer Epidemiology and Prevention Biomarkers. - 2009. Vol. 18. - № 5. - P. 1531-1537.

48. Morton L.M., Wang S.S., Richesson D.A., Schatzkin A., Hollenbeck A.R., Lacey J.V. Reproductive factors, exogenous hormone use and risk of lymphoid neoplasms among women in the National Institutes of Health - AARP Diet and Health Study Cohort // International journal of cancer. - 2009. - Vol. 124. - № 11. - P. 2737-2743.

49. Farabmandlou $N$. Association of testosterone with colorectal cancer (ht29), human glioblastoma (a172) and human embryonic kidney (hek293) cells proliferation // Acta Endocrinologica (Bucharest). - 2017. - Vol. 13. № 2. - P. 144 .

50. Shinder B.M., Shupe A., Lee G.T., Stein M.N., Kim I.Y., Singer E.A. Role of the androgen signaling axis in genitourinary malignancies // Translational cancer research. - 2018. - Vol. 7. - № 4. - P. 1135.

51. Karami S., Daugherty S.E., Schonfeld S.J., Park Y., Hollenbeck A.R., Grubb R.L., Hofmann J.N., Chow W., Purdue M.P. Reproductive factors and kidney cancer risk in 2 US cohort studies, 1993-2010 // American journal of epidemiology. 2013. - Vol. 177. - № 12. - P. 1368-1377.

52. Modi P.K., Farber N.J., Singer E.A. Precision oncology: identifying predictive biomarkers for the treatment of metastatic renal cell carcinoma // Translational cancer research. - 2016. - Vol. 5. - Suppl. 1. - P. S76. 
53. Ha Y.S., Lee G.T., Modi P., Kwon Y.S., Abn H., Kim W., Kim I.Y. Increased expression of androgen receptor mRNA in human renal cell carcinoma cells is associated with poor prognosis in patients with localized renal cell carcinoma // The Journal of urology. - 2015. - Vol. 194. - № 5. - P. 1441-1448.

54. Schweizer M., Yu E. AR-signaling in human malignancies: prostate cancer and beyond // Cancers. - 2017. Vol. 9. - № 1. - P. 7.

55. Dobruch J., Daneshmand S., Fisch M., Lotan Y., Noon A., Resnick M.J., Shariat S.F., Zlotta A.R., Boorjian S.A. Gender and bladder cancer: a collaborative review of etiology, biology, and outcomes // European urology. - 2016. Vol. 69. - № 2. - P. 300-310.

56.Shiota M., Kiyoshima K., Yokomizo A., Takeuchi A., Kashiwagi E., Dejima T., Takahashi R., InokuchiJ., Tatsugami K., Eto M. Suppressed recurrent bladder cancer after androgen suppression with androgen deprivation therapy or $5 \alpha$-reductase inhibitor // The Journal of urology. - 2017. - Vol. 197. - № 2. - P. 308-313.

57. Angioli R., Luvero D., Armento G., Capriglione S., Plotti F., Scaletta G., Lopez S., Montera R., Gatti A., Serra G., Benedetti Panici P., Terranova C. Hormone replacement therapy in cancer survivors: Utopia? // Critical reviews in oncology/ hematology. - 2018. - Vol. 124. - P. 51-60.

58. ColN.F., Hirota L.K., OrrR.K., Erban J.K., WongJ.B., LauJ. Hormone replacement therapy after breast cancer: a systematic review and quantitative assessment of risk // Journal of Clinical Oncology. - 2001. - Vol. 19. - № 8. - P. 2357-2363.

59. Fablén M., Fornander T., Johansson H., Johansson U., Rutqvist L., Wilking N., von Schoultz E. Hormone replacement therapy after breast cancer: 10 year follow up of the Stockholm randomised trial // European journal of cancer. 2013. - Vol. 49. - № 1. - P. 52-59.

60. Lupo M., Dains J.E., Madsen L.T. Hormone replacement therapy: an increased risk of recurrence and mortality for breast cancer patients? // Journal of the advanced practitioner in oncology. - 2015. - Vol. 6. - № 4. - P. 322.

61. Medras M., Alicja F., Pawel J., Jacek W., Teresa S.W. Breast cancer and long-term hormonal treatment of male hypogonadism // Breast cancer research and treatment. - 2006. - Vol. 96. - № 3. - P. 263-265.

62.Barakat R.R., Bundy B.N., Spirtos N.M., Bell J., Mannel R.S. Randomized double-blind trial of estrogen replacement therapy versus placebo in stage I or II endometrial cancer: a Gynecologic Oncology Group Study // Journal of clinical oncology. - 2006. - Vol. 24. - № 4. - P. 587-592.

63. Shim S.H., Lee S.J., Kim S.N. Effects of hormone replacement therapy on the rate of recurrence in endometrial cancer survivors: a meta-analysis // European journal of cancer. - 2014. - Vol. 50. - № 9. - P. 1628-1637.

64. Eeles R.A., Morden J.P., Gore M., Mansi J., Glees J., Wenczl M., Williams C., Kitchener H., Osborne R., Gutbrie D., Harper P., Bliss J.M. Adjuvant hormone therapy may improve survival in epithelial ovarian cancer: results of the AHT randomized trial // Obstetrical \& Gynecological Survey. - 2016. - Vol. 71. - № 4. - P. 223-224.

65. Pergialiotis V., Pitsouni E., Prodromidou A., Frountzas M., Perrea D.N., Vlachos G.D. Hormone therapy for ovarian cancer survivors: systematic review and meta-analysis // Menopause. - 2016. - Vol. 23. - № 3. - P. 335-342.

66. Mascarenhas C., Lambe M., Bellocco R., Bergfeldt K., Riman T., Persson I., Weiderpass E. Use of hormone replacement therapy before and after ovarian cancer diagnosis and ovarian cancer survival // International journal of cancer. - 2006. - Vol. 119. - № 12. - P. 2907-2915.

67. Kuble C.L., KapoorE., Sood R., Thielen J.M., JatoiA., Faubion S.S. Menopausal hormone therapy in cancer survivors: a narrative review of the literature // Maturitas. - 2016. - Vol. 92. - P. 86-96.

68. Finch A., Evans G., Narod S.A. BRCA carriers, prophylactic salpingo-oophorectomy and menopause: clinical management considerations and recommendations // Women’s health. - 2012. - Vol. 8. - № 5. - P. 543-555.

69. Raub L.A., Pannone A.F., Cantrell L.A. Hormone replacement therapy after treatment for cervical cancer: Are we adhering to standard of care? // Gynecologic oncology. - 2017. - Vol. 147. - № 3. - P. 597-600.

70. Драудин-Крыленко В.А., Заридзе Д.Г., Юрченко В.А., Мукерия А.Ф. Влияние эндогенного и экзогенного тестостерона на риск заболевания раком предстательной железы и на уровень простатспецифического антигена (ПСА): результаты мета-анализа // Материалы IV Петербургского международного онкологического форума «Белые ночи 2018». - 2018. - С. 228-228.

71. Roddam A.W., Allen N.E., Appleby P., Key T.J., Ferrucci L., Carter H.B., Metter E.J., Chen C., Weiss N.S., Fitzpatrick A., Hsing A.W., Lacey J.V.Jr., Helzlsouer K., Rinaldi S., Riboli E., Kaaks R., Janssen J.A., Wildhagen M.F., Schröder F.H., Platz E.A., Pollak M., Giovannucci E., Schaefer C., Quesenberry C.P.Jr., Vogelman J.H., Severi G., English D.R., Giles G.G., Stattin P., Hallmans G., Johansson M., ChanJ.M., Gann P., Oliver S.E., Holly J.M., Donovan J., Meyer F., Bairati I., Galan P. Insulin-like growth factors, their binding proteins, and prostate cancer risk: analysis of individual patient data from 12 prospective studies // Annals of internal medicine. - 2008. - Vol. 149. - № 7. - P. 461-471.

72. Snyder P.J., Bhasin S., Cunningham G.R., Matsumoto A.M., Stephens-Shields A.J., Cauley J.A., Gill T.M., BarrettConnor E., Swerdloff R.S., Wang C., Ensrud K.E., Lewis C.E., Farrar J.T., Cella D., Rosen R.C., Pahor M., Crandall J.P., Molitch M.E., Cifelli D., Dougar D., Flubarty L., Resnick S.M., Storer T.W., Anton S., Basaria S., Diem S.J., Hou X., Mohler E.R., Parsons J.K., Wenger N.K., Zeldow B., Landis J.R., Ellenberg S.S. Effects of testosterone treatment in older men // New England Journal of Medicine. - 2016. - Vol. 374. - № 7. - P. 611-624.

73. Morgentaler A., Traish A.M. Shifting the paradigm of testosterone and prostate cancer: the saturation model and the limits of androgen-dependent growth // European urology. - 2009. - Vol. 55. - № 2. - P. 310-321.

74. Pastuszak A.W., Pearlman A.M., Lai W.S., Godoy G., Sathyamoorthy K., Liu J.S., Miles B.J., Lipshultz L.I., Khera M. Testosterone replacement therapy in patients with prostate cancer after radical prostatectomy // The Journal of urology. - 2013. - Vol. 190. - № 2. - P. 639-644. 
75. Bandak M., Jorgensen N., Juul A., Vogelius I.R., Lauritsen J., Kier M.G., Mortensen M.S., Glovinski P., Daugaard G. Testosterone deficiency in testicular cancer survivors-a systematic review and meta-analysis // Andrology. 2016. - Vol. 4. - № 3. - P. 382-388.

76. Abu Zaid M.I., Menendez A.G., El Charif, O., Fung C., Monahan P.O., Feldman D.R., Hamilton R.J., Vaughn D.J., Beard C., Cook R., Althouse S.K., Sesso H.D., Ardeshirroubanifard S., Dinh P.C., Einhorn L., Fosså S., Travis L.B. Adverse Health Outcomes in Relationship to Hypogonadism After Chemotherapy: A Multicenter Study of Testicular Cancer Survivors // Journal of the National Comprehensive Cancer Network. - 2019. - Vol. 17. - № 5. - P. 459-468.

\section{References}

1.Baber R.J., Panay N., FentonA. 2016 IMS Recommendations on women's midlife health and menopause hormone therapy. Climacteric. 2016; 19(2): 109-150. doi: 10.3109/13697137.2015.1129166.

2. Doble G., Colpi G., Hargreave T., Papp G., Jungwirth A,. Weidner W. EAU Guidelines on Male Infertility. Eur Urol. 2005; 48(5): 703-711. doi: 10.1016/j.eururo.2005.06.002.

3. Bhasin S., Brito J.P., Cunningham G.R., Hayes F.J., Hodis H.N., Matsumoto A.M., Snyder P.J., Swerdloff R.S., Wu F.C., Yialamas M.A. Testosterone Therapy in Men With Hypogonadism: An Endocrine Society Clinical Practice Guideline. The Journal of Clinical Endocrinology \& Metabolism. 2018; 103(5): 1715-1744. doi: 10.1210/jc.2018-00229.

4. Subih G.T., Smetnik V.P., Andreeva E.N., Balan V.E., Gavisova A.A., Grigoryan O.R., Ermakova E.I., Il'ina L.M., Marchenko L.A., Rogovskaya R.I., Smetnik A.A., Yureneva R.V. Menopausal hormone therapy and maintaining the health of mature women. Clinical recommendations: protocols. Clinical recommendations (treatment protocol). Moscow, 2017. (In Russ)

5. Pinkerton J.V., Sánchez Aguirre F., Blake J., Cosman F., Hodis H.N., Hoffstetter S., Kaunitz A.M., Kingsberg S.A., Maki P.M., Manson J.E., Marchbanks P., McClung M.R., Nachtigall L.E., Nelson L.M., Pace D.T., Reid R.L., Sarrel P.M., Shifren J.L., Stuenkel C.A., Utian W.H. The 2017 hormone therapy position statement of The North American Menopause Society. Menopause. 2017; 24(7): 728-753. doi: 10.1097/gme.0000000000000921.

6. Webber L., Davies M., Anderso P. ESHRE Guideline: management of women with premature ovarian insufficiency. Human Reproduction. 2016; 31(5): 926-937. doi: 10.1093/humrep/dew027.

7. Cobin R.H., Goodman N.F. American association of clinical endocrinologists and American college of endocrinology position statement on menopause-2017 update. Endocrine Practice. 2017; 23(7): 869-880. doi: 10.4158/ep171828.ps

8. Dimopoulou C., Ceausu I., Depypere H., Lambrinoudaki I., Mueck A., Pérez-López F.R., Rees M., van der Schouw Y.T., Senturk L.M., Simonsini T., Stevenson J.C., Stute P., Goulis D.G. EMAS position statement: Testosterone replacement therapy in the aging male. Maturitas. 2016; 84: 94-99. doi: 10.1016/j.maturitas.2015.11.003.

9. Alyaev Yu.G., Glybochko P.V., Pushkarya D.Yu. Urology. Russian clinical guidelines. 2017. (In Russ)

10.Dedov I.I., Mel'nichenko G.A., Rozbivanov R.V., Kurbatov D.G. The recommendations on diagnostics and treatment of male hypogonadism (deficit of testosterone). The project. Problems of Endocrinology. 2015; 61(5): 60-71. doi: 10.14341/probl201561560-71. (In Russ)

11. Roman L.A., Nascimento C., Oliveira D.Y., Porto C.F.A. Age at natural menopause and mortality: A survival analysis of elderly residents of São Paulo, Brazil. Maturitas. 2018; 117: 29-33. doi: 10.1016/j.maturitas.2018.08.012.

12. Ruige J.B., Ouwens D.M., Kaufman J.M. Beneficial and Adverse Effects of Testosterone on the Cardiovascular System in Men. The Journal of Clinical Endocrinology \& Metabolism. 2013; 98(11): 4300-4310. doi: 10.1210/ jc.2013-1970.

13. Gunn H.M., Rinne I., Emilsson H., Gabriel M., Maguire A.M., Steinbeck K.S. Primary Gonadal Insufficiency in Male and Female Childhood Cancer Survivors in a Long-Term Follow-Up Clinic. J Adolesc Young Adult Oncol. 2016; 5(4): 344-350. doi: 10.1089/jayao.2016.0007.

14. Chisholm J., Hough R., Soanes L. A Practical Approach To The Care Of Adolescents And Young Adults With Cancer. 2018.

15. MunozJ., Wheler J.J., Kurzrock R. Androgen receptors beyond prostate cancer: an old marker as a new target. Oncotarget. 2014; 6(2). doi: 10.18632/oncotarget.2831.

16. Deli T., Orosz M., Jakab A. Hormone Replacement Therapy in Cancer Survivors - Review of the Literature. Pathology \& Oncology Research. 2019. doi: 10.1007/s12253-018-00569-x.

17. Bogush T.A., Dudko E.A., Beme A.A., Bogush E.A., Polotsky B.E., Tyulyandin R.A., Davydov M.I. Estrogen Receptor Expression in Tumors Different from Breast Cancer. Antibiotics and Chemotherapy. 2009; 54(7-8): 41-49. (In Russ)

18. Hsu L.H., Chu N.M., Kao S.H. Estrogen, Estrogen Receptor and Lung Cancer. Int J Mol Sci. 2017; 18(8): 1713. doi: $10.3390 /$ ijms 18081713 .

19. Ganti A.K., Sahmoun A.E., Panwalkar A.W., Tendulkar K.K., PottiA. Hormone Replacement Therapy Is Associated With Decreased Survival in Women With Lung Cancer. Journal of Clinical Oncology. 2006; 24(1): 59-63. doi: 10.1200/ jco.2005.02.9827.

20. Clague J., Reynolds P., Henderson K.D., Sullivan-Halley J., Ma H., Lacey J., Chang S., Delclos G.L., Du X., Forman M.R., Bernstein L. Menopausal Hormone Therapy and Lung Cancer-Specific Mortality Following Diagnosis: The California Teachers Study. PLoS one. 2014; 9(7): e103735. doi: 10.1371/journal.pone.0103735. 
21. Hyde Z., Flicker L., McCaul K.A., Almeida O.P., Hankey G.J., Chubb S.A.P., Yeap B.B. Associations between Testosterone Levels and Incident Prostate, Lung, and Colorectal Cancer. A Population-Based Study. Cancer Epidemiology Biomarkers \& Prevention. 2012; 21(8): 1319-1329. doi: 10.1158/1055-9965.epi-12-0129.

22. Jung K., Park J.C., Kang H., Brandes J.C. Androgen deprivation therapy is associated with decreased second primary lung cancer risk in the United States veterans with prostate cancer. Epidemiol Health. 2018; 40: e2018040. doi: 10.4178/epih.e2018040.

23. Blitshteyn S., Crook J.E., Jaeckle K.A. Is There an Association Between Meningioma and Hormone Replacement Therapy? Journal of Clinical Oncology. 2008; 26(2): 279-282. doi: 10.1200/jco.2007.14.2133.

24. Benson V.S., Kirichek O., Beral V., Green J. Menopausal hormone therapy and central nervous system tumor risk: Large UK prospective study and meta-analysis. Int J Cancer. 2014; 136(10): 2369-2377. doi: 10.1002/ijc.29274.

25. Wigertz A., Lönn S., Mathiesen T., Ablbom A., Hall P., Feychting M. Risk of Brain Tumors Associated with Exposure to Exogenous Female Sex Hormones. Am J Epidemiol. 2006; 164(7): 629-636. doi: 10.1093/aje/kwj254.

26. Schildkraut J.M., Calvocoressi L., Wang F., Wrensch M., Bondy M.L., Wiemels J.L., Claus E.B. Endogenous and exogenous hormone exposure and the risk of meningioma in men. J Neurosurg. 2014; 120(4): 820-826. doi: 10.3171/2013.12.jns131170.

27. Rodríguez-Lozano D.C., Piña-Medina A.G., Hansberg-Pastor V., Bello-Alvarez C., Camacho-Arroyo I. Testosterone Promotes Glioblastoma Cell Proliferation, Migration, and Invasion Through Androgen Receptor Activation. Front Endocrinol (Lausanne). 2019; 10. doi: 10.3389/fendo.2019.00016.

28. Ross J.A., Sinner P.J., Blair C.K., Cerban J.R., Folsom A.R. Hormone replacement therapy is not associated with an increased risk of leukemia (United States). Cancer Causes \& Control. 2005; 16(5): 483-488. doi: 10.1007/s10552004-7117-z.

29. Hinds L., Price J. Menopause, hormone replacement and gynaecological cancers. Menopause Int. 2010; 16(2): 89-93. doi: 10.1258/mi.2010.010018.

30. Howell S.J., Radford J.A., Adams J.E., Smets E.M.A., Warburton R., Shalet S.M. Randomized placebo-controlled trial of testosterone replacement in men with mild Leydig cell insufficiency following cytotoxic chemotherapy. Clin Endocrinol (Oxf). 2001; 55(3): 315-324. doi: 10.1046/j.1365-2265.2001.01297.x.

31.Botteri E., Støer N.C., Weiderpass E., Pukkala E., Ylikorkala O., Lyytinen H. Menopausal hormone therapy and risk of melanoma: a nationwide register-based study in Finland. Cancer Epidemiology Biomarkers \& Prevention. 2019: cebp.0554.2019. doi: 10.1158/1055-9965.epi-19-0554.

32. MacKie R.M., Bray C.A. Hormone replacement therapy after surgery for stage 1 or 2 cutaneous melanoma. $\mathrm{Br}$ J Cancer. 2004; 90(4): 770-772. doi: 10.1038/sj.bjc.6601595.

33. Morvillo V., Lüthy I.A., Bravo A.I., Capurro M.I., Portela .P, Calandra R., Mordob J. Androgen receptors in human melanoma cell lines IIB-MEL-LES and IIB-MEL-IAN and in human melanoma metastases. Melanoma Res. 2002; 12(6): 529-538. doi: 10.1097/00008390-200212000-00002.

34. Caboon E.K., Kitahara C.M., Ntowe E., Bowen E.M., Doody M.M., Alexander B.H., Lee T., Little M.P., Linet M.S., Freedman D.M. Female Estrogen-Related Factors and Incidence of Basal Cell Carcinoma in a Nationwide US Cohort. Journal of Clinical Oncology. 2015; 33(34): 4058-4065. doi: 10.1200/jco.2015.62.0625.

35. Moleti M., Sturniolo G., Di Mauro M., Russo M., Vermiglio F. Female Reproductive Factors and Differentiated Thyroid Cancer. Front Endocrinol (Lausanne). 2017; 8. doi: 10.3389/fendo.2017.00111.

36. Yakushevskaya O.V., Yureneva R.V., Protasova A.E., Khabas G.N., Ashrafyan L.A. Menopausal hormone therapy and nongynecological cancer (neoplasms of the digestive organs). Obstetrics and Gynecology: News, Opinions, Training. 2019; 7(1): 52-60. doi: 10.24411/2303-9698-2019-11007. (In Russ)

37. Wibowo E., Schellhammer P., Wassersug R.J. Role of Estrogen in Normal Male Function: Clinical Implications for Patients With Prostate Cancer on Androgen Deprivation Therapy. Journal of Urology. 2011; 185(1): 17-23. doi: 10.1016/j.juro.2010.08.094.

38.Zhu Y., Yue D., Yuan B., Zhu L., Lu M. Reproductive factors are associated with oesophageal cancer risk. European Journal of Cancer Prevention. 2017; 26(1): 1-9. doi: 10.1097/cej.0000000000000234.

39. Brusselaers N., Maret-Ouda J., Konings P., El-Serag H.B., Lagergren J. Menopausal hormone therapy and the risk of esophageal and gastric cancer. Int J Cancer. 2017; 140(7): 1693-1699. doi: 10.1002/ijc.30588.

40. Cooper S.C., Trudgill N.J. Subjects with prostate cancer are less likely to develop esophageal cancer: analysis of SEER 9 registries database. Cancer Causes \& Control. 2012; 23(6): 819-825. doi: 10.1007/s10552-012-9950-9.

41. Sukocheva O.A. Androgens and esophageal cancer: What do we know? World J Gastroenterol. 2015; 21(20): 6146. doi: 10.3748/wjg.v21.i20.6146.

42. Kim H.W., Kim J., Lim B.J., Kim H., Kim H., ParkJ.J., Youn Y.H., Park H., Nob S.H., Kim J.W., Choi S.H. Sex Disparity in Gastric Cancer: Female Sex is a Poor Prognostic Factor for Advanced Gastric Cancer. Ann Surg Oncol. 2016; 23(13): 4344-4351. doi: 10.1245/s10434-016-5448-0.

43. Kominea A., Konstantinopoulos P.A., Kapranos N., Vandoros G., Gkermpesi M., Andricopoulos P., Artelaris S., Savva S., Varakis I., Sotiropoulou-Bonikou G., Papavassiliou A.G. Androgen receptor (AR) expression is an independent unfavorable prognostic factor in gastric cancer. J Cancer Res Clin Oncol. 2004; 130(5): 253-258. doi: 10.1007/s00432003-0531-x.

44. Shi L., Feng Y., Lin H., Ma R., Cai X. Role of estrogen in hepatocellular carcinoma: is inflammation the key? J Transl Med. 2014; 12(1): 93. doi: 10.1186/1479-5876-12-93. 
45. Fernandez E., Gallus S., Bosetti C., Franceschi S., Negri E., La Vecchia C. Hormone replacement therapy and cancer risk: A systematic analysis from a network of case-control studies. Int J Cancer. 2003; 105(3): 408-412. doi: 10.1002/ijc.11083.

46. Ma W., Lai H., Yeb S., Cai X., Chang C. Androgen receptor roles in hepatocellular carcinoma, fatty liver, cirrhosis and hepatitis. Endocr Relat Cancer. 2014; 21(3): R165-R182. doi: 10.1530/erc-13-0283.

47. Prentice R.L., Pettinger M., Beresford S.A., Wactawski-Wende J., Hubbell F.A., Stefanick M.L., Cblebowski R.T. Colorectal Cancer in Relation to Postmenopausal Estrogen and Estrogen Plus Progestin in the Women's Health Initiative Clinical Trial and Observational Study. Cancer Epidemiology Biomarkers \& Prevention. 2009; 18(5): 15311537. doi: 10.1158/1055-9965.epi-08-1209.

48. Morton L.M., Wang S.S., Richesson D.A., Schatzkin A., Hollenbeck A.R., Lacey J.V. Reproductive factors, exogenous hormone use and risk of lymphoid neoplasms among women in the National Institutes of Health-AARP Diet and Health Study Cohort. Int J Cancer. 2008; 124(11): 2737-2743. doi: 10.1002/ijc.24248.

49. Farabmandlou N. Association of Testosterone with Colorectal Cancer (HT29), Human Glicoblastoma (A172) and Human Embryonic Kidney (HEK293) Cells Proliferation. Acta Endocrinologica (Bucharest). 2017; 13(2): 144149. doi: $10.4183 /$ aeb.2017.144.

50. Shinder B.M., Shupe A., Lee G.T., Stein M.N., Kim I.Y., SingerE.A. Role of the androgen signaling axis in genitourinary malignancies. Transl Cancer Res. 2018; 7(4): 1135-1142. doi: 10.21037/tcr.2018.03.41.

51.Karami S., Daugherty S.E., Schonfeld S.J., Park Y., Hollenbeck A.R., Grubb R.L., Hofmann J.N., Chow W., Purdue M.P. Reproductive Factors and Kidney Cancer Risk in 2 US Cohort Studies, 1993-2010. Am J Epidemiol. 2013; 177(12): 1368-1377. doi: 10.1093/aje/kws406.

52. Modi P.K., Farber N.J., Singer E.A. Precision oncology: identifying predictive biomarkers for the treatment of metastatic renal cell carcinoma. Transl Cancer Res. 2016; 5(S1): S76-S80. doi: 10.21037/tcr.2016.06.05.

53. Ha Y.S., Lee G.T., Modi P., Kwon Y.S., Abn H., Kim W., Kim I.Y. Increased Expression of Androgen Receptor mRNA in Human Renal Cell Carcinoma Cells is Associated with Poor Prognosis in Patients with Localized Renal Cell Carcinoma. Journal of Urology. 2015; 194(5): 1441-1448. doi: 10.1016/j.juro.2015.03.078.

54. Schweizer M., Yu E. AR-Signaling in Human Malignancies: Prostate Cancer and Beyond. Cancers (Basel). 2017; 9(12): 7. doi: 10.3390/cancers9010007.

55.Dobruch J., Daneshmand S., Fisch M., Lotan Y., Noon A., Resnick M.J., Shariat S.F., Zlotta A.R., Boorjian S.A. Gender and Bladder Cancer: A Collaborative Review of Etiology, Biology, and Outcomes. Eur Urol. 2016; 69(2): 300-310. doi: 10.1016/j.eururo.2015.08.037.

56. Shiota M., Kiyoshima K., Yokomizo A., Takeuchi A., Kashiwagi E., Dejima T., Takahashi R., Inokuchi J., Tatsugami K., Eto M. Suppressed Recurrent Bladder Cancer after Androgen Suppression with Androgen Deprivation Therapy or $5 \alpha$-Reductase Inhibitor. Journal of Urology. 2017; 197(2): 308-313. doi: 10.1016/j. juro.2016.08.006.

57. Angioli R., Luvero D., Armento G., Capriglione S., Plotti F., Scaletta G., Lopez S., Montera R., Gatti A., Serra G., Benedetti Panici P., Terranova C. Hormone replacement therapy in cancer survivors: Utopia? Crit Rev Oncol Hematol. 2018; 124: 51-60. doi: 10.1016/j.critrevonc.2018.02.005.

58. Col N.F., Hirota L.K., Orr R.K., Erban J.K., Wong J.B., Lau J. Hormone Replacement Therapy After Breast Cancer: A Systematic Review and Quantitative Assessment of Risk. Journal of Clinical Oncology. 2001; 19(8): 2357-2363. doi: 10.1200/jco.2001.19.8.2357.

59. Fablén M., Fornander T., Johansson H., Johansson U., Rutqvist L., Wilking N., von Schoultz E. Hormone replacement therapy after breast cancer: 10 year follow up of the Stockholm randomised trial. Eur J Cancer. 2013; 49(1): 52-59. doi: 10.1016/j.ejca.2012.07.003.

60. Lupo M., Dains J.E., Madsen L.T. Hormone Replacement Therapy: An Increased Risk of Recurrence and Mortality for Breast Cancer Patients? J Adv Pract Oncol. 2015; 6(4). doi: 10.6004/jadpro.2015.6.4.3.

61. Medras M., Alicja F., Pawel J., Jacek W., Teresa S.W. Breast cancer and long-term hormonal treatment of male hypogonadism. Breast Cancer Res Treat. 2006; 96(3): 263-265. doi: 10.1007/s10549-005-9074-y.

62. Barakat R.R., Bundy B.N., Spirtos N.M., Bell J., Mannel R.S. Randomized Double-Blind Trial of Estrogen Replacement Therapy Versus Placebo in Stage I or II Endometrial Cancer: A Gynecologic Oncology Group Study. Journal of Clinical Oncology. 2006; 24(4): 587-592. doi: 10.1200/jco.2005.02.8464.

63. Shim S.H., Lee S.J., Kim S.N. Effects of hormone replacement therapy on the rate of recurrence in endometrial cancer survivors: A meta-analysis. Eur J Cancer. 2014; 50(9): 1628-1637. doi: 10.1016/j.ejca.2014.03.006.

64. Eeles R.A., Morden J.P., Gore M., Mansi J., Glees J., Wenczl M., Williams C., Kitchener H., Osborne R., Gutbrie D., Harper P., Bliss J.M. Adjuvant Hormone Therapy May Improve Survival in Epithelial Ovarian Cancer. Obstet Gynecol Surv. 2016; 71(4): 223-224. doi: 10.1097/ogx.0000000000000308.

65. Pergialiotis V., Pitsouni E., ProdromidouA., Frountzas M., Perrea D.N., Vlachos G.D. Hormone therapy for ovarian cancer survivors. Menopause. 2016; 23(3): 335-342. doi: 10.1097/gme.0000000000000508.

66. Mascarenhas C., Lambe M., Bellocco R., Bergfeldt K., Riman T., Persson I., Weiderpass E. Use of hormone replacement therapy before and after ovarian cancer diagnosis and ovarian cancer survival. Int J Cancer. 2006; 119(12): 2907-2915. doi: 10.1002/ijc.22218.

67. Kuble C.L., Kapoor E., Sood R., Thielen J.M., JatoiA., Faubion S.S. Menopausal hormone therapy in cancer survivors: A narrative review of the literature. Maturitas. 2016; 92: 86-96. doi: 10.1016/j.maturitas.2016.07.018. 
68. Finch A., Evans G., Narod S.A. BRCA Carriers, Prophylactic Salpingo-Oophorectomy and Menopause: Clinical Management Considerations and Recommendations. Women's Health. 2012; 8(5): 543-555. doi: 10.2217/whe.12.41.

69. Raub L.A., Pannone A.F., Cantrell L.A. Hormone replacement therapy after treatment for cervical cancer: Are we adhering to standard of care? Gynecol Oncol. 2017; 147(3): 597-600. doi: 10.1016/j.ygyno.2017.09.009.

70. Draudin-Krylenko V.A., Zaridze D.G., Yurchenko V.A, Mukeriya A.F. The effect of endogenous and exogenous testosterone on the risk of prostate cancer and on the level of prostate-specific antigen (PSA): results of a metaanalysis. Materials of the IV St. Petersburg International Cancer Forum «White Nights 2018». 2018: 228. (In Russ)

71. Roddam A.W., Allen N.E., Appleby P., Key T.J., Ferrucci L., Carter H.B., Metter E.J., Chen C., Weiss N.S., Fitzpatrick A., Hsing A.W., Lacey J.V.Jr., Helzlsouer K., Rinaldi S., Riboli E., Kaaks R., Janssen J.A., Wildhagen M.F., Schröder F.H., Platz E.A., Pollak M., Giovannucci E., Schaefer C., Quesenberry C.P.Jr., Vogelman J.H., Severi G., English D.R., Giles G.G., Stattin P., Hallmans G., Johansson M., Chan J.M., Gann P., Oliver S.E., Holly J.M., Donovan J., Meyer F., Bairati I., Galan P. Insulin-like Growth Factors, Their Binding Proteins, and Prostate Cancer Risk: Analysis of Individual Patient Data from 12 Prospective Studies. Ann Intern Med. 2008; 149(7): 461. doi: 10.7326/0003-4819-149-7-200810070-00006.

72. Snyder P.J., Bhasin S., Cunningham G.R., Matsumoto A.M., Stephens-Shields A.J., Cauley J.A., Gill T.M., BarrettConnor E., Swerdloff R.S., Wang C., Ensrud K.E., Lewis C.E., Farrar J.T., Cella D., Rosen R.C., Pahor M., Crandall J.P., Molitch M.E., Cifelli D., Dougar D., Fluharty L., Resnick S.M., Storer T.W., Anton S., Basaria S., Diem S.J., Hou X., Mohler E.R., Parsons J.K., Wenger N.K., Zeldow B., Landis J.R., Ellenberg S.S. Effects of Testosterone Treatment in Older Men. New England Journal of Medicine. 2016; 374(7): 611-624. doi: 10.1056/nejmoa1506119.

73. Morgentaler A., Traish A.M. Shifting the Paradigm of Testosterone and Prostate Cancer: The Saturation Model and the Limits of Androgen-Dependent Growth. Eur Urol. 2009; 55(2): 310-321. doi: 10.1016/j.eururo.2008.09.024.

74. Pastuszak A.W., Pearlman A.M., Lai W.S., Godoy G., Sathyamoorthy K., Liu J.S., Miles B.J., Lipshultz L.I., Khera M. Testosterone Replacement Therapy in Patients with Prostate Cancer After Radical Prostatectomy. Journal of Urology. 2013; 190(2): 639-644. doi: 10.1016/j.juro.2013.02.002.

75. Bandak M., Jørgensen N., Juul A., Vogelius I.R., Lauritsen J., Kier M.G., Mortensen M.S., Glovinski P., Daugaard G. Testosterone deficiency in testicular cancer survivors - a systematic review and meta-analysis. Andrology. 2016; 4(3): 382-388. doi: 10.1111/andr.12177.

76. Abu Zaid M.I., Menendez A.G., El Charif, O., Fung C., Monaban P.O., Feldman D.R., Hamilton R.J., Vaughn D.J., Beard C., Cook R., Althouse S.K., Sesso H.D., Ardeshirrouhanifard S., Dinh P.C., Einhorn L., Fosså S., Travis L.B. Adverse health outcomes in relationship to hypogonadism (HG) after platinum-based chemotherapy: A multicenter study of North American testicular cancer survivors (TCS). Journal of Clinical Oncology. 2019; 17(5): 459-468. doi: 10.1200/ jco.2017.35.18_suppl.lba10012. 